\title{
Energy Absorption Buildup Factor Studies In Some Soils
}

\author{
Vishal Pathak ${ }^{1}$, Gurdeep Singh Sidhu ${ }^{2}$ \\ ${ }^{I}$ (Department of Physics, Singhania University, Rajasthan, India) \\ ${ }_{2}^{2}$ (Government Sports School, Ghudda (Bathinda), India)
}

\begin{abstract}
An attempt is made to generate effective atomic number, energy absorption buildup factor (EABF) in the energy region 0.015-15.0 MeV up to a penetration depth of $40 \mathrm{mfp}$ for some soils. The five parameters geometrical progression $(G-P)$ fitting approximation has been used to calculate energy absorption build-up factor (EABF). The generated energy absorption buildup factors has been studied as function of incident photon energy \& penetration depth and represented graphically.
\end{abstract}

Index Terms: Energy absorption build-up factor (EABF), Mean free path (mfp), Effective atomic number $\left(Z_{\text {eff }}\right.$ ), Equivalent atomic number (Zeq).

\section{INTRODUCTION}

Today, to benefit mankind, the radiations are used in basic sciences, medicine, and industry and for generating electricity Gamma radiations occupy the highest energy among the electromagnetic radiations. The exposure to gamma radiations with human body can occur during radiological diagnosis, nuclear reactors \& nuclear research establishments .The use of radiations can be biologically hazardous, there is need of restrict and controlled exposure of human beings to these radiations by using shields of proper dimensions and of an appropriate material. The study has been focused on build-up factor which plays major role during interaction of gamma rays with the chosen soils. Nuclear accidents due to natural and manmade disasters cannot be refused in future. To avoid any hazard from day to day exposure of radiation the choice of material is very important for the purpose of shielding of radiations. People involved in industries, institutions \& research labs may be the victim of gamma ray exposure. For the safety of people \& selection of shielding materials, build-up factors study become important. When gamma radiations interact with material through Compton scattering. The scattering results in accumulation of photons in the interacting material due to which the number of photons buildup in the materials. Two types of build-up factors namely energy absorption build-up factor (EABF) \& exposure build-up factor (EBF). The concept of buildup factor was mutually introduced by White [1] and Fano [2] recognized its importance in attenuation studies. To calculate build-up factor there are different methods like G.P. fitting method. Harima et al. 1986 [3], invariant embedding method, Shimizu, 2002 [4]; Shimizu et al., 2004 [5], iterative method, Suteau and Chiron, 2005 [6] and Monte Carlo method, Sardari et al., 2009 [7]. Recently American National standards ANSI/ANS-6.4.3[8] has provided buildup factor data for 23 elements, one compound and two mixtures (i.e. air and water) and concrete at energies in the range $0.015-15 \mathrm{MeV}$ up to penetration depths of $40 \mathrm{mfp}$ by using the G.P method. D.Sardari and S. Baradaran 2010 [9] calculated buildup factor of gamma and $\mathrm{X}$-ray photon the energy range of $0.2-2.0 \mathrm{MeV}$ in water and soft tissue using Monte Carlo code MCNP4C. The results are compared with buildup factor data of pure water. In each case very small deviation is observed.

There are successful contributions which are based on the buildup factor studies in some soils and ceramic materials available in the literature. For example, Brar et al. [10] have studied the variation of buildup factors of soils with weight fractions of iron and silicon. Sidhu et al. [11] have studied the energy and effective atomic number dependence of the exposure buildup factors in biological samples. Manohara et al. [12] studied the variation of exposure buildup factors for heavy metal oxide glass with photon energy and penetration depth.

Singh et al. [13] studied the energy dependence of total photon attenuation coefficients of composite materials Sidhu et al. [14] have studied the energy and effective atomic number dependence of the exposure build-up factors in biological samples J. S. Dhillon et al.[15] have studied Gamma Ray Photon Energy Absorption build-up Factor In Some Soil

\section{MATERIALS AND METHODS}

\section{A. Selection of Materials}

In present investigation The composition of soils has been taken from literature Lotse $e t$. al.,[16] to study the energy absorption build-up factor (EABF) of different soil samples from some selected states of India, The chemical compositions of these soils are given in Table 1. Soils can be used as good radiation shielding material 
because of their low cost and easy availability. As build up factor data for these samples is not available in any form, so energy absorption build-up factor (EABF) of the chosen soil samples has been calculated for incident photon energy from $0.015-15.0 \mathrm{MeV}$ and up to a penetration depth of $40 \mathrm{mfp}$.

Table 1. Percentage Chemical Composition of the chosen soil samples

\begin{tabular}{|l|l|l|l|l|}
\hline $\begin{array}{l}\text { Chemical } \\
\text { composition } \\
\text { Of soil }\end{array}$ & $\begin{array}{l}\text { Red Soil } \\
\text { (Bangalore) } \\
\text { S1 }\end{array}$ & $\begin{array}{l}\text { Red Soil } \\
\text { (Thiruvallam) } \\
\text { S2 }\end{array}$ & $\begin{array}{l}\text { Black Soil } \\
\text { (Coimbatore) } \\
\text { S3 }\end{array}$ & $\begin{array}{l}\text { Black } \\
\text { Soil } \\
\text { (Indore) } \\
\text { S4 }\end{array}$ \\
\hline $\mathrm{SiO}_{2}$ & 54.34 & 50.44 & 59.80 & 62.46 \\
\hline $\mathrm{Al}_{2} \mathrm{O}_{3}$ & 28.70 & 35.70 & 17.40 & 18.90 \\
\hline $\mathrm{Fe}_{2} \mathrm{O}_{3}$ & 16.00 & 20.00 & 8.00 & 10.00 \\
\hline $\mathrm{CaO}$ & 1.12 & 1.68 & 4.62 & 4.48 \\
\hline $\mathrm{P}_{2} \mathrm{O}_{5}$ & 0.06 & 0.09 & 0.09 & 0.08 \\
\hline $\mathrm{K} 2 \mathrm{O}$ & 1.80 & 2.72 & 3.85 & 2.71 \\
\hline $\mathrm{MgO}$ & 0.21 & 0.23 & 0.21 & 0.23 \\
\hline
\end{tabular}

\section{B. Computational Work:}

Build-up factors are computed by using G.P. fitting parameters and the equivalent atomic number Zeq of selected soil samples following three steps given below:

Step1. Calculations for equivalent atomic number (Zeq):

To compute equivalent atomic number of chosen soil samples, the value of Compton partial attenuation coefficient $\left(\mu_{\text {compton }}\right)$ and total attenuation coefficient $\left(\mu_{\text {total }}\right)$ in $\mathrm{cm} 2 / \mathrm{g}$ are obtained for selected samples in the energy range of 0.015 to $15.0 \mathrm{MeV}$ by using the state of art and convenient computer program WinXCOM computer program Gerward et al. [17]; Gerward et al. [18]) initially developed as XCOM, Berger and Hubbel, [19]. Ratio $R$ ( $\mu$ compton/ $\mu$ total) for selected samples is calculated at energies 0.015 to $15.0 \mathrm{MeV}$ using a simple computer program. For the interpolation of Zeq for selected samples, the ratio $\mathrm{R}$ of particular sample at a given energy is matched with the corresponding ratio of elements at the same energy. For the case, where the ratio $\mathrm{R}$ lies between two successive ratios of known elements, the value of Zeqis interpolated using following formula, Sidhu et al., [20] The value of $Z_{\mathrm{eq}}$ was interpolated by using the following formula of interpolation:

$Z_{\mathrm{eq}}=\frac{Z_{1}\left(\log \mathrm{R}_{2}-\log \mathrm{R}\right)+\mathrm{Z}_{2}\left(\log \mathrm{R}-\log \mathrm{R}_{1}\right)}{\log \mathrm{R}_{2}-\log \mathrm{R}_{1}}$

Where $\mathrm{Z} 1$ and $\mathrm{Z} 2$ are the elemental atomic numbers corresponding to the ratios $\left(\mu_{\text {comp }} / \mu\right.$ total) $\mathrm{R} 1$ and $\mathrm{R} 2$ respectively and $\mathrm{R}$ is ratio for given material at a particular energy. The computed Zeq for selected soil samples is given in table 2 .

Table 2 Equivalent atomic numbers (Zeq) of soil samples

\begin{tabular}{|c|c|c|c|c|c|}
\hline Sr No & $\begin{array}{c}\text { Energy } \\
\text { MeV }\end{array}$ & RB & $\begin{array}{l}\frac{\text { Equivalent }}{\frac{\text { atomic }}{\text { number }}} \\
\text { RT }\end{array}$ & BC & BI \\
\hline & & S1 & S2 & $\mathbf{S 3}$ & S4 \\
\hline 1 & 0.015 & 14.49 & 14.64 & 13.53 & 13.72 \\
\hline 2 & 0.02 & 14.71 & 14.88 & 13.68 & 13.89 \\
\hline 3 & 0.03 & 14.93 & 15.1 & 13.86 & 14.13 \\
\hline 4 & 0.04 & 15.07 & 15.27 & 13.98 & 14.21 \\
\hline 5 & 0.05 & 15.19 & 15.37 & 14.06 & 14.32 \\
\hline
\end{tabular}




\begin{tabular}{|cccccc|}
6 & 0.06 & 15.27 & 15.51 & 14.17 & 14.4 \\
7 & 0.08 & 15.4 & 15.64 & 14.21 & 14.45 \\
8 & 0.1 & 15.54 & 15.78 & 14.29 & 14.59 \\
9 & 0.15 & 15.49 & 15.49 & 13.98 & 14.92 \\
10 & 0.2 & 16.92 & 16.92 & 14.49 & 14.49 \\
11 & 0.3 & 16.99 & 16.99 & 14.5 & 14.5 \\
12 & 0.4 & 16.5 & 16.5 & 14.5 & 14.5 \\
13 & 0.5 & 16.5 & 16.5 & 14.5 & 14.5 \\
14 & 0.6 & 16.5 & 16.5 & 14.5 & 14.5 \\
15 & 0.8 & 16.5 & 16.5 & 14.5 & 14.5 \\
16 & 1 & 16.5 & 16.5 & 14.5 & 14.5 \\
17 & 1.5 & 16.5 & 16.5 & 14.5 & 14.5 \\
18 & 2 & 12.92 & 12.94 & 12.88 & 12.88 \\
19 & 3 & 12.66 & 12.66 & 11.72 & 11.72 \\
20 & 4 & 12.39 & 12.39 & 11.94 & 11.94 \\
21 & 5 & 12.57 & 12.57 & 11.99 & 11.99 \\
22 & 6 & 12.29 & 12.29 & 11.92 & 11.92 \\
23 & 8 & 12.49 & 12.49 & 12.16 & 12.16 \\
24 & 10 & 12.28 & 12.42 & 11.73 & 11.91 \\
25 & 15 & 12.5 & 12.62 & 11.89 & 12.01 \\
\hline
\end{tabular}

\section{Step2 - Computation of G-P fitting function parameters}

The G.P fitting parameters were calculated by simple process of interpolation. These parameters were then used to generate energy absorption buildupfactor for soil samples by using the formula which is given by Harima et al [21] for chosen energy range of 0.015 to $15.0 \mathrm{MeV}$.and upto a penetration depth of 40 mean free path. The computed values of Zeq for the chosen samples of soil were used to interpolate G- P fitting function parameters for the energy absorption buildup factors in chosen energy range ( 0.015 to $15.0 \mathrm{MeV})$ and penetration depth( 1 $40 \mathrm{mfp}$ ) . The formula, Sidhu et al., [20] used for the purpose of interpolation of the G.P. fitting parameters is given below:

$$
P=\frac{P_{1}\left(\log Z_{2}-\log Z_{\text {eq }}\right)+P_{2}\left(\log Z_{\text {eq }}-\log Z_{1}\right)}{\log Z_{2}-\log Z_{1}}
$$

where P1 and P2 are the values of G.P. fitting parameters corresponding to atomic number Z1 and Z2 respectively at a given energy and Zeq is the equivalent atomic number of chosen soils at same energy

\section{step3 - Computation of Energy absorption build-up factors}

The G-P fitting parameters were then used to generate energy absorption build-up factor for the chosen samples for energy range of 0.015 to $15.0 \mathrm{MeV}$. using the following G.P fitting formula given by Harima et al. [21]

$\mathrm{B}(\mathrm{E}, \mathrm{x})=1+\frac{(\mathrm{b}-1)\left(\mathrm{k}^{\mathrm{x}}-1\right)}{\mathrm{K}-1}$ for $\mathrm{K} \neq 1$

$\mathrm{B}(\mathrm{E}, \mathrm{x})=1+(\mathrm{b}-1) \mathrm{x}$ for $\mathrm{K}=1$

$\mathrm{K}(\mathrm{E}, \mathrm{x})=\mathrm{cx}^{\mathrm{a}}+\mathrm{d}_{-} \frac{\tanh \left(\mathrm{x} / \mathrm{x}_{\mathrm{k}}-2\right)-\tanh (-2)}{1-\tanh (-2)} \mathrm{x} \leq 40 \mathrm{mfp}$

Where $\mathrm{E}$ is the incident photon energy, $\mathrm{x}$ is the penetration depth in mean free path and b,c,a, $\mathrm{X}_{\mathrm{k}}$ and $\mathrm{d}$ are G-P fitting parameters. The parameter $\mathrm{K}(\mathrm{E}, \mathrm{x}$ ) represents photon dose multiplication and change in the shape of spectrum with increasing penetration depth. $\mathrm{K}$ is represented by tangent hyperbolic function of penetration depth in mfpHere the mean free path $(\mathrm{mfp})$ is defined as the average distance that photons of a given energy travel before an two successive interactions in a given medium occur. It is equal to the reciprocal of the attenuation coefficient. The ratio of the total value of a specified radiation quantity at any point to the 
contribution to that value from radiation reaching the point without having undergone any collision is called "buildup factor".

\section{Results and discussion}

The chemical composition of chosen soils is listed in Table 1. Table 2 shows the obtained equivalent atomic numbers of the chosen soil samples. The generated energy absorption build-up factor EABF values for soil samples have been shown in graphical form at fixed penetration depth (Figs. 1 to 4 ) as well as at fixed energy values (Figs. 5 to 8 ) and (Figs 9 to 12)., The generated energy absorption build-up factor values are plotted against the penetration depth (mfp) for chosen soil samples for energy from .015 to $15 \mathrm{MeV}$ with penetration depth up to 40mfp.From present results it is concluded that for chosen soil samples the energy absorption buildup factor $(\mathrm{EABF})$ increases with increase in penetration depth. It is also seen that the Energy absorption buildup factor values are extremely large for low energies nearly up to $0.1 \mathrm{MeV}$, and increases with greater penetration depth. The increase in energy absorption build-up factor with penetration depth is small for low energies' and for high energies it increases rapidly.

\section{Effect of Incident Photon Energy on Energy Absorption Buildup Factor (EABF)}

From Figs. 1 to 4 it has been observed that EABF values of chosen soils start increasing with increase in photon energy up to a maximum energy at intermediate energies and then further start decreasing with increase in energy of gamma ray. Here the low value of buildup factor around $0.015 \mathrm{MeV}$ is due to predominance of photo electric effect in this energy region which results in fast removal of low energy photons, thereby not allowing these photons to buildup. It is further observed that in the energy range $0.15 \mathrm{MeV}$ to $0.8 \mathrm{MeV}$ the buildup factor values are high for a given penetration depth due to dominance of Compton effect. Which only helps in the degradation of photon energy and fails to remove a photon completely. Because of multiple scattering of photons they exist for longer time in material which leads to a higher value of buildup factor. Here it is also observed that at gamma ray energy $0.2 \mathrm{MeV}$, buildup factor value is very high because of exclusive dominance of Compton effect. Furthermore it is also observed that for energies greater than $2.0 \mathrm{MeV}$, the dominance of pair production phenomenon over Compton effect increases, so values of buildup factor decreases. The variation of EABF with incident photon energy seem to be independent of chemical composition of chosen soils beyond $2.0 \mathrm{MeV}$ respectively.

0.010 .1

\section{Effect of Penetration Depth on Energy Absorption Buildup Factor}

The values of EABF of chosen soils increase with the increase in penetration depth. At lowest photon energy $0.015 \mathrm{MeV}$ EABF values are low because of dominance of photoelectric effect, but at $0.2 \mathrm{MeV}$ photon energy EABF values are much higher due to dominance of Compton effect. It can also be seen, at photon energy 5 and $15 \mathrm{MeV}$ EABF values are low due to predominance of pair- production as in (figs. 5 to 8 ).

The curves of different energies show that there is continuous increase in EABF with increase in penetration depth for all soil samples. It is due to the fact that the increase in penetration depth increases the interaction of gamma-radiation photons with matter which results in generation of large number of low energy photons due to occurrence of Compton scattering process. The values of EABF of chosen soil increases with increase in penetration depth between 15 to $40 \mathrm{mfp}$ at energy range of 5-15 MeV. The reason behind the pair production process starts pre- dominating and results with an electron-positron pair for lower penetration depth, these particles may escape from the material or after multiple collisions with in the material comes to rest and further annihilates. With the increase in penetration depth, these secondary gamma rays (as a result of annihilation) contribute to the rise in intensity of the primary gamma rays

\section{Effect of Effective Atomic Number on EABF}

As in Table 2 every soil have different Zeq at various energy levels, so to assign a particular atomic number to each material, mean of Zeq of each sample at various photon energies is calculated and mean so calculated is treated as the effective atomic number i.e. Zeff of that soil

$\mathrm{Z}_{\mathrm{eff}}=\frac{\sum_{B=0.015}^{15.0} \mathrm{Zeq}}{25}$

Values of Zeff of Soil samples i.e $\mathrm{S}_{1}, \mathrm{~S}_{2}, \mathrm{~S}_{3}$ and $\mathrm{S}_{4}$ are 14.76, 14.83,13.51 and 13.64 respectively. This is very helpful in studying the behavior of buildup factor of different chosen soils at fixed penetration depths and fixed photon energy. 


\section{Conclusions}

This study of build-up factor of chosen soils will be helpful in estimating the transport and degradation of gamma radiations in these chosen soil samples.Generaly Lead and Mercury are used as shielding materials. But due to their high cost and non availability these are difficult to use at large scale. Soils can be used as a gammaray shielding material in field experiments which is suitable from the point of view of cost and availability. Above studies projects Soil as a potential radiation shielding material

\section{Acknowledgment}

The authors are grateful to Berger and Hubbell for providing the convenient computer program XCOM/WinXcom with the help of National Institute of Standards and Technology, Gaithersburg.
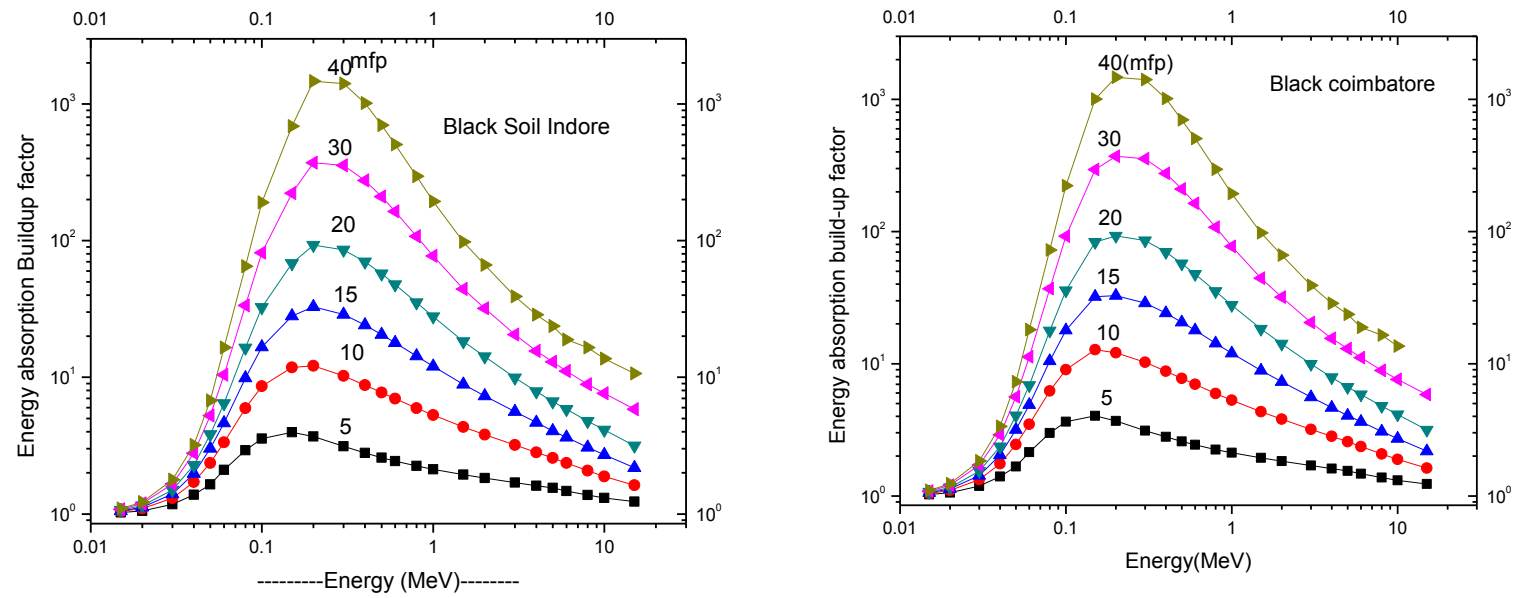

Figure 1 Variation of energy absorption build-up factor with incident photon energy(MeV)

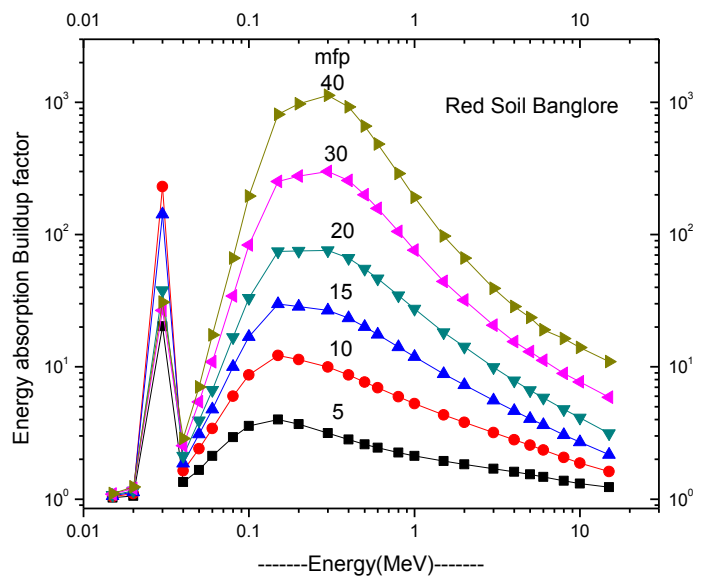

Figure 3 Variation of energy absorption build-up factor with incident photon energy(MeV)

Figure 2 Variation of energy absorption buildupfactor with incident photon energy(MeV)

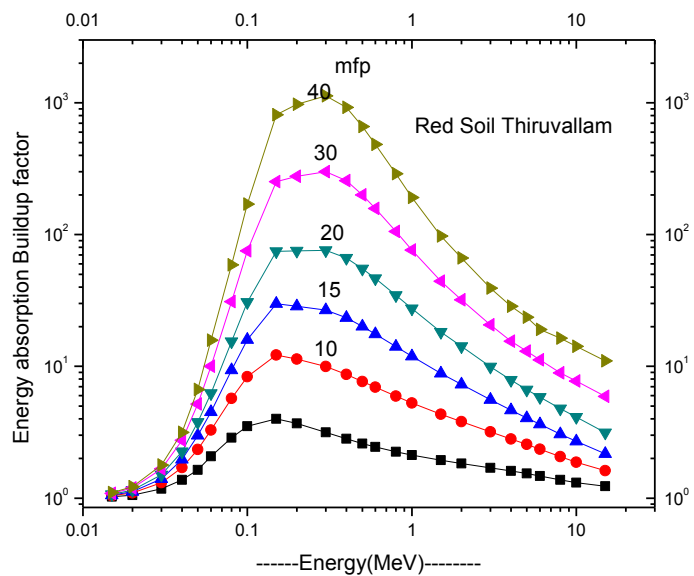

Figure 4 Variation of energy absorption build-up factor with incident photon energy(MeV) 


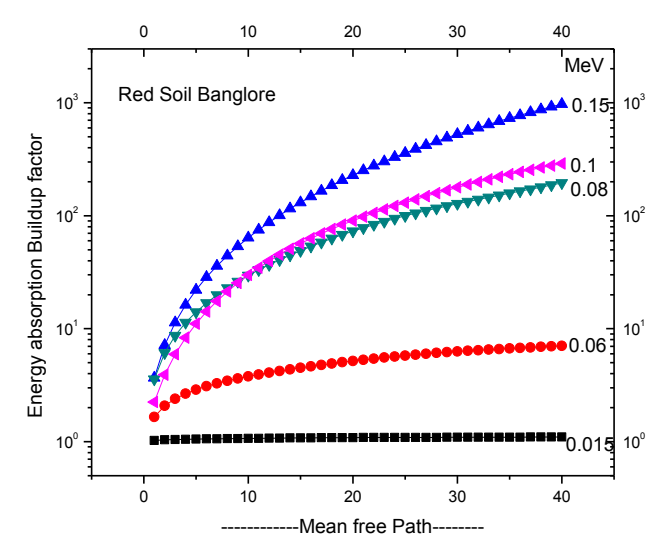

Fig. 5 The EABF for soils upto 40mfp

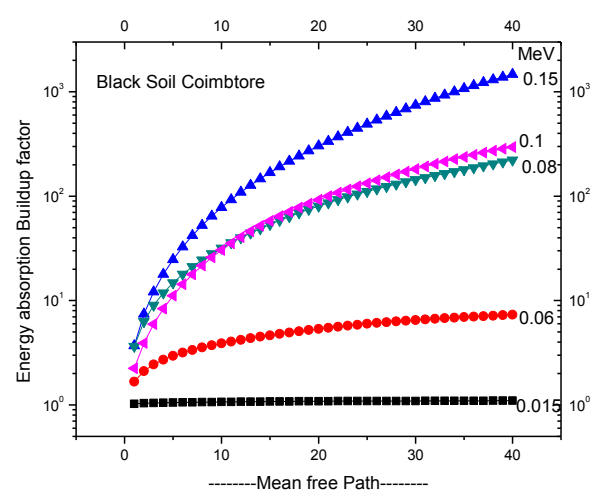

Fig. 7 The EABF for soils upto 40mfp

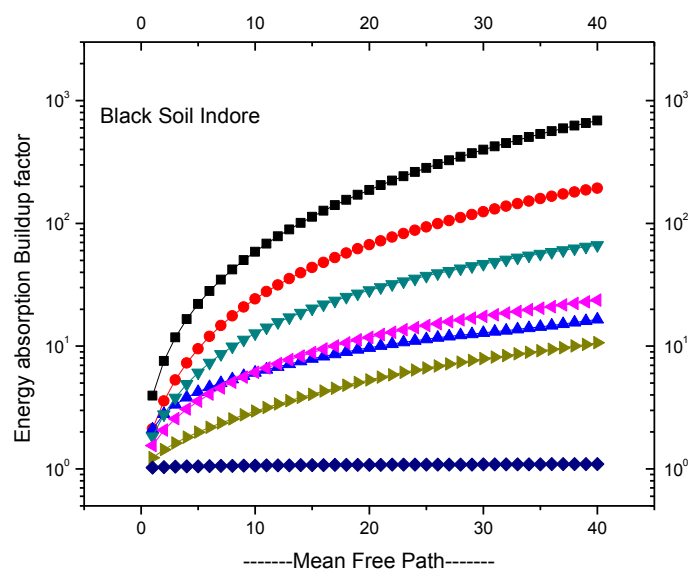

Fig. 9 The EABF for soils upto 40mfp

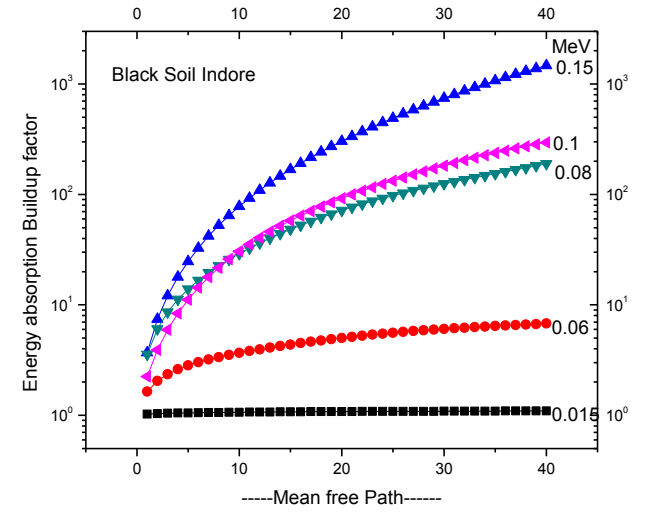

Fig. 6 The EABF for soils upto 40mfp

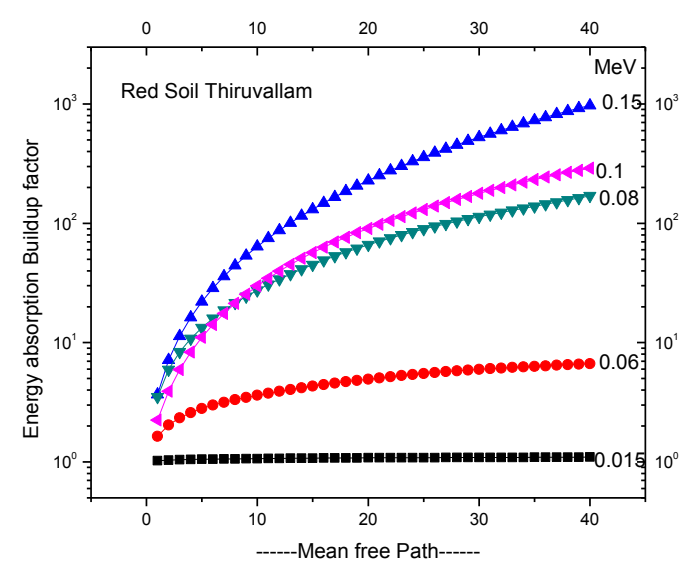

Fig. 8 The EABF for soils upto 40mfp

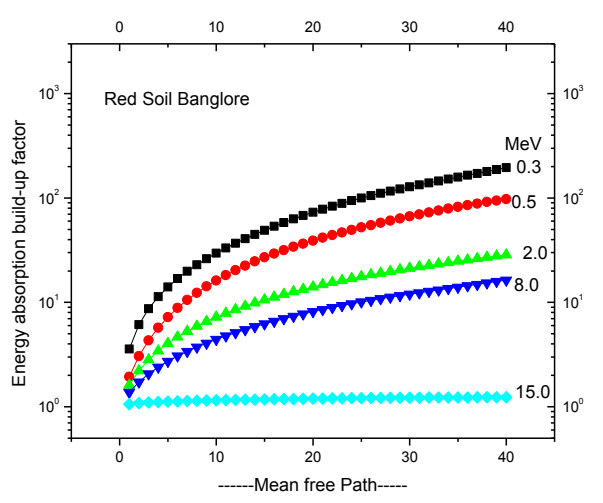

Fig.10 The EABF for soils upto 40mfp 


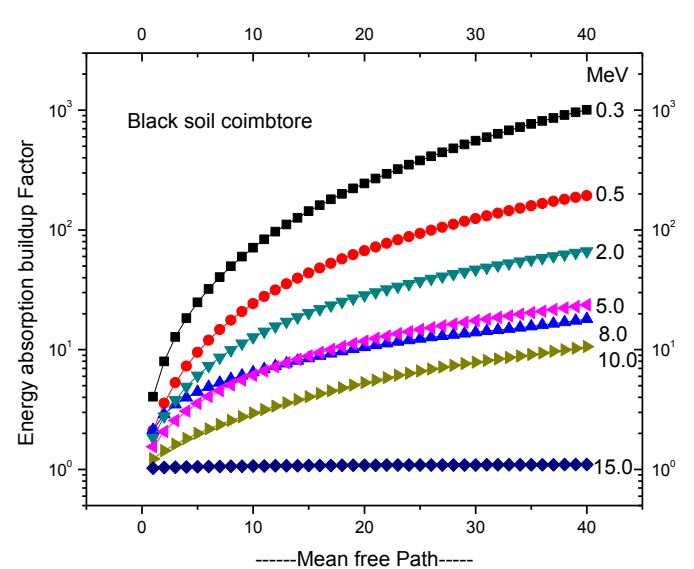

Fig.11 The EABF for soils upto 40mfp

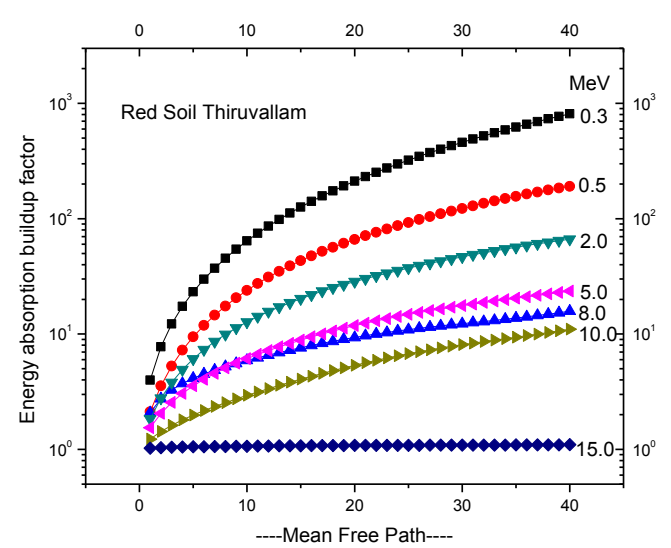

Fig.12 The EABF for soils upto 40mfp

\section{References}

[1] White, G. R.,The penetration and deffusion of ${ }^{60} \mathrm{Co} \gamma$-rays in water using spherical geometry,Rev. 80, $1950,154$.

[2] Fano, U., $\Gamma$-ray attenuation part II-analysis of penetration,Nucleonics 11, 1953, 55.

[3] Harima, Y. and Sakamoto, Y,. Validity of the geometric progression formula in approximating the gamma ray build-up factors. Nucl. Sci. Eng. 94, 1986, 24 - 35.

[4] Shimizu, A., . Calculations of gamma ray buildup factors up to depths of $100 \mathrm{mfp}$ by the method of invariant embedding, (I) analysis of accuracy and comparison with other data. J.Nucl. Sci. Technol. 39, 2002, 477- 486,.

[5] Shimizu, A., Onda, T., Sakamoto, Y.,. Calculations of gamma ray buildup factors up to depths of $100 \mathrm{mfp}$ by the method of invariant embedding, (III) generation of an improved data set. J. Nucl. Sci. Technol. 41, 2004,413 - 424.

[6] Suteau, C., Chiron, M.,. An iterative method for calculating gamma ray buildup factors in multi-layer shields. Radiat. Prot. Dosim. $116,2005,489-492$.

[7] Sardari,D., Abbaspour,A., Baradaran, S., Babapour, F.,. Estimation of gamma and X-ray photons buildup factor in soft tissue with Monte Carlo method. Appl. Radiat. Isot. 67, 2009,1438 - 1440,

[8] ANSI/ANS-6.4.3, gamma ray attenuation coefficient and buildup factors for engineering materials, American Nuclear Society, LaGrange Park, Illinois.,1991

[9] Sardari,D and S.baradaran Semi empirical relationship for photon buildup factor in soft tissue and water. Radiation protection dosimetry 10.1093/rpd/ncq 212, 2010.

[10] Brar, G.S., Sidhu, G.S.,Sandhu P.S., Mudahar, G.S., Variation of buildup factors of soil with weight fractions of Iron andsilicon.,Appl. Radiat. Isot., 49, 1998, 977-980.

[11] Sidhu, G.S, Singh P.S, Mudahar G.S, J. radiol. Prot., 20, 2000, 53.

[12] Manohara S.R, Hanagodimath S.M, Gerward L., Mittal K.C,Exposure buildup factors of heavy metal oxide glass:A radiation Shield Journal of the Korean Physical Society, 59, no. 2, 2011, 2039-2042.

[13] Singh M., Mudahar G.S,Energy dependence of total photon attenuation coefficients of composite material, Int. J. Appl. Radiat. Isot. (U.S.A.), 43, 1992, 907

[14] Sidhu G.S, Singh P.S, Mudahar G.S, Radiol J. Prot. 20, 200053.

[15] Dhillon, Singh Barjinderpal and Sidhu G.S Gamma Ray Photon Energy Absorption Buildup Factor Study In Some Soils (IOSRJAP)ISSN - 2278-4861, 2012)

[16] Lotse E.G. , N.P. Datta ,K..P. Tomar and M.R .Motsra,Mineralogical Composition of some Red and Black soils of india ,Nuclear Research Laboratory,Indian Agricultural Research Institute ,www.iari.res.in, 1974

[17] Gerward, L., Guilbert, N., Jensen, K. Levring,H.,. X-ray absorption in matter. Reengineering XCOM. Radiat. Phys. Chem., 2001, $60,23-24$

[18] Gerward, L., Guilbert, N., Jensen, K. B., Levring, H.et al., Win XCom- A program for calculating attenuation coeffiecients. Radiat. Phys. Chem. 71, 2004, 653- 654.

[19] Berger, M.J., Hubbell, J.H.,. XCOM:Photon Cross-Sections Database,Web Version 1.2, National Institute of Standards and Technology, Gaithersburg, MD20899, USA. http://physics.nist.gov/xcom (Originally published as NBSIR 87-3597'XCOM: Photon Cross Sections on a Personal Computer") 1987/1999

[20] Sidhu G.S, Singh Parjit and Mudahar G. S. Effect of absorber thickness and beam divergence on gamma-ray buildup factor. Indian J. Phys. 74A (5), 2000, 505-507.

[21] Y. Harima,Y.Sakamoto, S. Tanaka, M. kawai, Nucl. Sci. Eng., 94, 1886, 24 